\title{
KESINLIK VE ÇERÇEVELEMENIN RISK TERCIHI ETKISi
}

\author{
İmran DEMiR*, Şeyda AKYOL**
}

\begin{abstract}
Özet
Bu çalışma, ihtimal teorisinin risk alma ve çerçeveleme etkisi konusundaki varsayılmalarının Türkiye'deki geçerlilik ve genellenebilirliğini tespit etmeyi amaçlamaktadır. Kahneman ve Tversky'nin orijinal çalışmalarından derlediğimiz bir grup soruyu Marmara Üniversitesi İletişim Fakültesi lisans programındaki öğrencilere uygulayarak, iki temel soruya yanıt aramaktayız. Öncelikle, bireylerin risk tercihleri ile ilgilenmekteyiz. Bu bağlamda, katılımcıların kazanç söz konusu iken riskten kaçınma; kayıp ile karşı karşıya kalınınca da, bireyin risk alma eğilimine sahip olup olmadığını anlamaya çalışmaktayız. Çerçeveleme etkisi olarak bilinen seçeneklerin farklı sunumunun tercihlerde yaptığı etki, cevap aradığımız ikinci soruyu oluşturmaktadır. Elde ettiğimiz bulgular, büyük ölçüde, ihtimal teorisinin varsayımları ve Kahneman ile Tversky'nin orijinal çalışmalarında elde ettiği bulgularla benzerlik göstermektedir.
\end{abstract}

Anahtar Kelimeler: kesinlik etkisi, çerçeveleme etkisi, risk, rasyonel seçim, ihtimal teorisi. 


\title{
RISK CHOICE EFFECT OF CERTAINTY AND FRAMING
}

\author{
İmran DEMiR*, Şeyda AKYOL**
}

\begin{abstract}
This research aims at exploring the validity and generalizability of Prospect theory's assumptions on risk taking and framing effect in Turkey. Applying a set of questions derived from the original investigation of Kahneman and Tversky to undergraduate students at Marmara University Faculty of Communication, we seek to answer two primary questions. In the first place, we are interested in variation in risk preferences of individuals. Specifically, we would like to see whether participants in our survey are risk averse in the domain of gain and risk seeking in the domain of losses. Second, we want to see whether the presentation format of a choice situation, known as framing effect, causes any variation in preferences of respondents. The investigation produces findings that are largely consistent with the assumptions of prospect theory and original findings on the topic.
\end{abstract}

Key Words: certainty effect, framing effect, risk, rational choice, prospect theory. 


\section{Giriş}

Bu çalışma, ihtimal teorisinin risk alma ve çerçeveleme etkisi konusundaki varsayımlarının Türkiye'deki geçerlilik ve genellenebilirliğini, kısmen de olsa, tespit etmeyi amaçlamaktadır. Kahneman ve Tversky'nin orijinal çalışmalarından derlediğimiz bir grup soruyu Marmara Üniversitesi İletişim Fakültesi lisans programındaki öğrencilere uygulayarak, iki temel soruya yanıt aramaktayız. Öncelikle bireylerin risk tercihleri ile ilgilenmekteyiz. Bu bağlamda katılımcıların, kazanç söz konusu iken riskten kaçınma; kayıp ile karşı karşıya kaIınınca da, risk alma eğilimine sahip olup olmadığını anlamaya çalışmaktayız. Çerçeveleme etkisi olarak bilinen seçeneklerin farklı sunumunun tercihlerde yaptığı etki, cevap aradığımız ikinci sorudur. Bu amaçla öncelikle, beklenen fayda teorisi üzerinden, ihtimal teorisinin kökenleri ve temel prensiplerine değinmekteyiz. Ardından da, araştırmamızda kullandığımız sorulardan elde ettiğimiz bulguları değerlendirmekteyiz.

\section{Rasyonel Seçim Kuramı ve ihtimal Teorisi}

Rasyonel seçim kuramı veya diğer adıyla beklenen fayda teorisi (expected utility theory [EUT]), çok basit bir ifade ile; bireylerin, yaptıkları seçimlerde rasyonel oldukları iddiasındadır. Rasyonaliteden kasıt bireylerin, fayda maliyet hesaplaması yaparak çıkarlarını maksimize edecek en fazla değeri ve gerçekleşme olasılığının en yüksek olduğu seçeneği tercih etmeleridir. Buna göre; bir seçimin tercih edilebilirliği veya beklenen değeri, değerin $(X)$ gerçekleşme olasılığıyla (p) çarpılmasıyla elde edilir. Formüle etmek gerekirse: $(E V=X p)$. Bu formülasyon, bireylerin tercihleri hakkında fikir sahibi olmak için psikolojik durumlarını, inançlarını, yani bir bakıma sorgulama yetilerini etkileyen yargılarını veya seçimlerini yaptıkları koşullarını bilmenin gerekli olmadığı; bireylerin tercihlerinin, onların inanç ve istekleri hakkında bilgi sahibi olmak için yeterli bir gösterge olduğu görüşündedir. Buna karşın Allais (1979) ile başlayan karşıt bir yaklaşım, bireylerin tercihlerini yaparken sistematik bir şekilde rasyonel seçim kuramının aksiyomlarını ihlal ettiklerini göstermiştir. Örneğin EUT, sunum şekli ne olursa olsun rasyonel bireylerin aynı seçenekleri tercih etmesi gerektiğini (invariance of choices) iddia ederken; Allais, bireylerin tercihlerinin sabit olmadığını ve sunum şekline göre farklılıklar gösterebileceğini ortaya koymuştur.

Aslında von Neuman ve Morgenstern (1944) tarafından aksiyomatik temeller üzerine oturtulan beklenen fayda teorisi, Bernoulli'nin fayda kavramına olasılıkları ekleyerek, faydayı öznel bir kavram olmaktan çıkarıp; nesnel bir nitelik kazandırma amacı taşır. Oysaki Bernoulli, bir maddenin nesnel değerinin (value), öznel değeri (utility) ile eşdeğer olmadığını; ederin nesnenin miktarına veya kullanımına göre değer yitirdiği gözleminden hareketle, değer ve 
varlık/servet (wealth) arasındaki ilişkinin doğru orantılı değil, içe bükümlü olduğu anlayışını ortaya atmıştır. Azalan marjinal fayda olarak bilinen bu ilişki, bireylerin tercihlerinde riskten kaçınma eğilimi taşıdıklarını ima eder.

Eğer insanlar, Bernoulli'nin azalan marjinal fayda eğrisine göre riskten kaçınma eğilimine sahipse; hem kumar oynayıp, hem de kendilerini kayıplara karşı sigortalatmak gibi birbiri ile taban tabana zıt iki eylemin yaygınlığı nasıl izah edilebilir? Friedman ve Savage (1948) bu paradoksu, yılan seklindeki yayvan bir eğri (wiggly curve) ile çözüme kavuşturmaya çalışmıştır. Bu eğriye göre sahip oldukları servet, insanların risk alma eğilimini belirleyen temel unsurdur. Görece yoksul olan insanlarda riskten kaçınma eğiliminin daha baskın olacağı ve bunun da yoksul insanları olası kayıplara karşı kendilerini sigortalatmaya yol açtığını; daha fazla servetin ise, varlıklı insanları daha riskli davranmaya sevk ettiğini, bunun da göreceli olarak varlıklı insanlarda kumar oynama eğilimini artırdığını ileri sürmüşlerdir.

Friedman ve Savage'ın (1948) bu varsayımının içinde barındırdığı çelişkileri görmek için çok fazla düşünmek gerekmiyor. Yoksullar da kumar oynadığı gibi, zenginler de kendilerini olası kayıplara karşı sigortalatmaktan kaçınmazlar. Bu çelişkilerden hareketle Markowitz (1952), risk alma eğiliminde farklılaşmaya yol açan temel etkenin servet değil, referans noktası olduğunu ortaya atmıştır. Sonradan ihtimal teorisinin önemli bir ayağını teşkil eden bu varsayıma göre, küçük kazanımlar insanlardaki fayda algısını pekiştirirken; büyük kazanımlarla bu fayda azalma göstermektedir.

Beklenen fayda teorisinin yetersizliği, bireylerin sadece değişik şartlar altında farklılaşma gösteren risk eğilimlerini açıklayamamayla sınırlı değildir. Markowitz'den bu yana birçok araştırmacı, bireylerin tercih yaparken rastlantısal olmayacak sıklıkta beklenen fayda teorisinin varsayımlarının aksine davranışlar sergilediğini göstermiştir (Bar-Hillel, 1973; Ellsberg, 1961; Fischhoff vd. 1981; Fishburn, 1988; Mosteller ve Nogee, 1951; Tversky, 1969, 1975).

Kahneman ve Tversky $(1979,1984)$, rasyonel seçim kuramında görülen bu sapmalardan hareketle, ihtimal teorisi (prospect theory) adını verdikleri ve bireylerin karar alırken hangi psikolojik süreçlerden etkilendiklerini çözüme kavuşturan sistematik bir yaklaşım ortaya koymuşlardır. İhtimal teorisinin üzerine kurulduğu iki temel varsayımdan söz etmek mümkündür. Öncelikle insanlar karar verirken, muhakeme kapasitesinden kaynaklanan yetersizliklerden dolayı, matematikçiler veya ekonomistler gibi fayda/maliyet hesaplaması yapmak yerine heuristic denen sezgisel bazı kısa yolların yardımına başvurmaktadır (Einhorn ve Hogarth, 1986; Hoagarth ve Makridakis, 1982; Tversky ve Kahneman, 1974). İhtimal teorisinin ikinci temel varsayımı; insanların tercihlerinin, tercihin yapıldığı koşullardan bağımsız düşünülemeyeceği- 
dir. Bir arada ele alındığında, bu iki tespitin çok önemli davranışsal sonuçları söz konusudur.

Kahneman ve Tversky $(1979,1984)$, konu hakkında yaptıkları sayısız çalışmada, bireylerin tercihlerinin seçim yaptıkları koşullara göre farklılık gösterdiğini gözlemlemiştir. Daha açık ifade etmek gerekirse, bireylerin tercihlerini belli referans noktalarına göre yaptıklarını ve bu referans noktalarının da kişilerin içinde bulundukları koşulları kayıp veya kazanç olarak kodlamalarına göre tercihlerde ciddi farklılıklara neden olabileceğini göstermişlerdir. Referans noktası belirlenmesinde çerçeveleme etkisinin (framing effect) büyük bir rolü bulunmaktadır. Tercih probleminin sunuluş sekline göre olumlu ya da olumsuz tanımlanmasının, bireylerde riskten kaçınma veya risk almayı teşvik edici bir etkiye sahip olduğu gözlemlenmiştir.

Ancak tercih ortamıyla (context) karar oluşturma süreci arasındaki yakın ilişki de bilinmektedir. Diğer yandan insanların karar oluşturma süreçlerinde bazı sezgisel faktörlerin de etkili olduğu saptanmıştır. Bu sezgisel kısa yolların başında kesinlik etkisi (certainty effect) gelir. Genel olarak insanlar belirsizlikten hoşlanmaz ve kaçınırlar. Bunun sonucu olarak 'kafesteki bir kuş, çalıdaki iki kuştan daha değerlidir' ifadesindeki gibi kesin sonuçları, olasılıksal sonuçlara tercih ederler. İnsanlarda belirsizliğe karşı temkinli olmanın temelinde ise, varlık etkisi (endowmant effect) ve kaybetmekten kaçınma (loss aversion) olguları yatmaktadır. 'Insanın eskisi kendisine kıymetlidir' ifadesine uygun düşecek şekilde bireyler, ellerindeki varlıklara (endowmant) henüz elde edilmemiş varlıklara nazaran daha fazla değer atfeder ve onları kolay kolay bırakmak istemezler. Diğer taraftan hiç kimse kaybetmekten hoşlanmaz. Öyle ki kaybetmenin verdiği acı, kazanmanın verdiği hazdan daha güçlüdür. Dolaysıyla varlık etkisi, kaybetmeden kaçınma etkisi ile bir arada düşünüldüğünde, insanlarda statükodan yana bir eğilimin hâkim olmasına yol açar.

Kahneman ve Tversky, bireylerin sistematik olarak sergilediği tüm bu tutumlar dikkate alındığında, bireylerin risk tercihlerinin, temelini Markowitz'in attığı S seklindeki bir eğri ile tasvir edilebileceğini ileri sürmüştür. Bu eğriye göre, S'nin üst yarısı insanların kazançlı veya olumlu durumlarla karşılaştığı şartlar karşısındaki risk eğilimini temsil ederken; altta kalan kısmı, negatif veya kaybetmenin söz konu olduğu şartlarda insanların risk eğilimini temsil eder. Daha açık bir ifade ile ihtimal teorisi, insanların olumlu şartlar altında risk almaktan kaçınacağını ve daha kesin sonuçları tercih edeceğini; olumsuzluk veya kaybın söz konusu olduğu durmalarda ise, risk alma konusunda istekli davranacaklarını iddia eder.

İhtimal teorisinin bireylerin risk alma eğilimleri konusundaki bu varsayımı birçok alanda sayısız çalışma ile desteklenmiş olsa bile, inşacı kuramın ger- 
çekliğin kurgusal ve öznel olduğu; dolayısıyla toplumdan topluma farklılık gösterdiği iddiası göz önünde bulundurulduğunda, insanların risk alma davranışları ve bir problemin sunum şeklinin verilen tepkilerde değişikliğe neden olup olmadığının kültürden kültüre veya toplumdan topluma farklılık gösterip göstermediği, üzerinde düşünülmesi gereken bir soru işareti olarak karşımıza çıkmaktadır. Eğer bireyler Kahneman ve Tversky'nin ihtimal teorisinde iddia ettiği gibi belli davranış kalıplarına göre hareket ediyorlarsa, aynı tercih ve tepkilerin kültürden bağımsız bir şekilde farklı toplumlardaki bireylerde gözlemlenmesi gerekir. Eğer insan içinde yaşadığı koşulların ve toplumun bir ürünüyse, bireylerin risk tercihlerinin, ihtimal teorisinin öngördüğünden sapmalar göstermesi gerekmektedir.

Bu çalışma, geçerliliği yaygın olarak kabul edilen ihtimal teorisi bulgularının başka ortamlardaki geçerliliği ve genellenebilirliğini test etmeyi amaçlamaktadır. Bu çerçevede iki temel soruya cevap aramaktayız. Öncelikle rasyonel seçim kuramına yöneltilen yaygın eleştirilerde ileri sürüldüğü gibi, bireylerin seçimlerindeki tercihlerin değişmezliği (invariance of choices) aksiyomunu ihlal edip etmediklerini gözlemek. Bir sorunun sunum şekli, yani durumun bir kayıp veya bir kazanç olarak tasvir edilmesi, insanların tercihlerinde değişikliğe gitmesine sebep olur mu? İkinci amacımı, bireylerin risk eğilimlerini test etmektir. Yani insanlar, ihtimal teorisinin öne sürdüğü gibi, kazançlı oldukları durumlarda riskten kaçınıp; kaybın söz konusu olduğu durumlarda risk almaya eğilimli midir? Bu sorulara yanıt bulmak için Kahneman ve Tversky'nin yaklaşık kırk yıl önce konuyla ilgili yapmış oldukları deneyleri, Marmara Üniversitesi İletişim Fakültesi öğrencilerine uygulayarak tekrar etmekteyiz. Elde edilen sonuçlar bu anlamda, kişilerin risk alma davranışlarının ve olaylara tepkilerinin kültürden kültüre farklılıklar gösterip göstermediği konusunda bir fikir verecektir.

\section{Kesinlik, Çerçeveleme Etkisi ve İnsanların Tercihleri}

Bu bölümde, Kahneman ve Tversky'nin bireylerin rasyonel seçim kuramı ya da beklenen fayda teorisinin öngördüğü davranış kalıplarındaki sapmaları göstermek için 1979 ve 1984'te yapmış oldukları çalışmalardan derlediğimiz ve 11 sorudan oluşan bir anketin sonuçlarını sunmaktayız. Her ne kadar Kahneman ve Tversky bu çalışmalarda beklenen fayda teorisinin birden fazla aksiyomunun ihlalini gösteriyor olsalar da, bu çalışmada temel olarak bireylerin risk alma davranışları üzerinde durduğumuz için, ankette yer verdiğimiz sorular kesinlik ve çerçeveleme etkisinin katılımcıların tercihleri üzerinde yaptığı etkiye odaklanmaktadır.

Anket, Marmara Üniversitesi İletişim Fakültesi lisans programının değişik düzeylerindeki 181 öğrenciye uygulandı. $N$, her bir soruya yanıt veren katı- 
lımcı sayısını; köşeli parantez içindeki rakamlar ise, her bir seçeneğin aldığı yanıtın yüzdelik oranını ifade etmektedir. Normal parantez içindeki rakamlar, Kahneman ve Tversky'nin orijinal çalışmalarında elde ettikleri yüzdelikleri göstermektedir. Elde ettiğimiz sonuçlar ve bu sonuçların değerlendirmesi aşağıdaki gibidir:

\section{Problem 1: $\mathbf{N}=181$}

A. $\% 33$ olasılıkla 2500 TL kazanma ihtimali

\%66 olasılıkla 2400 TL kazanma intimali

\%1 olasılıkla hiçbir şey kazanmama intimali

B. Kesin 2400 TL kazanma intimali

Problem 1'de sunulan iki seçenekten A seçeneği olası bir sonuç öngörürken; B seçeneği kesin bir sonucu temsil etmektedir. Beklenen fayda teorisinin kazancı en çoklaştırma prensibine göre, katılımcıların faydası yüksek olan seçeneği $(.33 u(2500)+.66 u(2400)>$ u(2400)); yani A'yı, B'ye tercih etmesi gerekirdi. Elde edilen sonuçlardan da anlaşılacağı üzere, katılımcıların \%75'i kesin sonuç (B)'yi olası sonuç (A)'ya tercih etmiştir. Daha genel bir ifade ile A'nın daha yüksek bir beklenen değere sahip olmasına rağmen kesin olan $B$ seçeneğinin tercih edilmesi, bireylerin kazanç söz konusu olduğu zaman riskten kaçınma eğilimine işaret etmektedir.

\section{Problem 2: $\mathbf{N}=181$}

A. \%33 olasılıkla 2500 TL kazanma şansı

\%67 olasılıkla hiçbir şey kazanmama

B. \%34 olasılıkla 2400 TL kazanma

\%66 olasılıkla hiçbir şey kazanmama

Ancak her iki seçenek Problem 2'de olasılıksal olarak sunulduğu zaman, katılımcıların çok az bir farkla yüksek olasılıklı seçeneği, düşük olasılıklı seçeneğe tercih ettiği görülmektedir. Aradaki fark anlamlı olamayacak kadar küçüktür. Oysaki ikinci problem için Kahneman ve Tversky'nin çalışmasındaki katılımcıların \%83'ü, A'yı B'ye tercih etmiştir. Problem 2 için elde edilen sonucun Kahneman ve Tversky'nin çalışmasında elde ettiği sonuçtan farklılık göstermesini, iki seçenek için verilen olasılık ve değerler arasındaki farkın birbirine oldukça yakın olmasına bağlamaktayız. Her iki seçenekteki olasılık ve değerlerin birbirine yakın olmasının katılımcıların her iki seçenekten birine kayıtsız kalmalarına neden olduğunu düşünmekteyiz. Şöyle ki, Problem 4'te görüleceği üzere, olasılıklar ve değerler arasındaki fark daha belirgin olduğunda elde edilen sonuçların Kahneman ve Tversky'nin bulguları ile benzerlik gösterdiği ortaya çıkmaktadır. 


\section{Problem 3: $\mathbf{N}=177$}

A. \%80 olasılıkla 4000 TL kazanma ihtimali

B. \%100 olasılıkla 3000 TL kazanma ihtimali

[76]

\section{Problem 4: $\mathbf{N}=181$}

A. \%20 olasılıkla 4000 TL kazanma ihtimali

B. \%25 ihtimalle 3000 TL kazanma ihtimali

Problem 3'te katılımcılar kesin sonuçlu seçeneği (B), olası sonuca (A) tercih ederken; Problem 4'te yüksek değerli seçeneği, yüksek olasılıklı seçeneğe tercih etmişlerdir. Problem 3 ve 4'te gözlemleneceği gibi; A seçenekleri arasında 80'den .20'ye olasılıksal bir azalma söz konusudur. B tercihlerinde ise, 1'den .25'e bir azalma görülmektedir. Bunun katılımcıların tercihlerinde ne oranda etkili olduğu kesin olarak ifade edilememekle birlikte, Kahneman ve Tversky bunu; \%100 olasılıktan \%25'e düşen bir olasılığın, \%80'den \%20'ye düşen bir olasılığa göre daha büyük bir etkiye sahip olmasıyla açıklamışlardır.

\section{Problem 5: $\mathbf{N}=181$}

A. \%50 olasılıkla İngiltere, Fransa ve İtalya'ya üç haftalık bir tatil kazanma fırsatı

B. İngiltere'ye bir hafta kesin ihtimalle bir tatil kazanma fırsatı

[67]

\section{Problem 6: $\mathbf{N}=178$}

A. \%5 olasılıkla İngiltere, Fransa ve İtalya'ya 1 haftalık tatil kazanma fırsatı

B. \%10 olasılıkla sadece İngiltere'ye bir tatil kazanma fırsatı

Katılımcıların kesin seçenekleri olası seçeneklere tercih ettiği, Problem 5 ve 6'da daha açık bir şekilde ortaya çıkmaktadır. Problem 5'te katılımcıların büyük bir çoğunluğu (\%67) kesin sonuçlu seçeneği, olası seçeneğe tercih etmiştir. Ancak seçenekler olası olarak sunulduğu zaman katılımcıların yüksek değerli seçenekleri, yüksek olasılıklı seçeneklere tercih ettiği gözlemlenmektedir. Bu durum aslında Problem 2 ve 4 için de geçerlidir. Kazanmanın söz konusu olduğu ve sonucun olası olduğu durumlarda katılımcılar yüksek değerli seçenekleri, yüksek olasılıklı seçeneklere tercih etmektedir.

\section{Kaybetme Olasılığının Risk Eğilimine Yaptığı Etki}

Hatırlanacağı üzere ihtimal teorisi, birey tercihlerinin duruma göre farklılık göstereceği ve bireylerin olumlu şartlar altında risk almaktan kaçınma eğilimi taşırken; yapılacak seçimin olumsuzlukla sonuçlanması durumunda, risk alma 
eğilimine sahip oldukları iddiasındadır. Problem 7, 8 ve 9, bireylerin olumsuzluklar karşısındaki risk alma eğilimlerini saptamayı amaçlamaktadır. Problem 7, kaybetme intimali söz konusu olduğunda, katılımcıların çoğunun olası seçeneği kesin seçeneğe tercih ederek; açık bir şekilde risk almayı tercih ettiklerini ortaya koymaktadır. Bu noktada dikkat edilmesi gereken husus, yukarıdaki problemlerde olduğu gibi kazanmanın söz konusu olduğu durumların aksine bireylerin olasılıksal sonuçları, kesin sonuçlara tercih etmesidir.

\section{Problem 7: $\mathbf{N}=180$}
A. $\% 80$ olasılıkla 4000 TL kaybetme intimali
B. Kesin 3000 TL kaybetme intimali

\section{Problem 8: $\mathbf{N}=180$}
A. $\% 20$ olasilıkla 4000 TL kaybetme ihtimali
B. \%25 olasılıkla 3000 TL kaybetme intimali

\section{Problem 9: $\mathbf{N}=180$}

A. $\% 90$ olasılıkla 3000 TL kaybetme ihtimali
B. $\% 45$ olasılıkla 6000 TL kaybetme ihtimali

Problem 8'de katılımcılar, \%25 olasılıkla 3000 TL kaybetme ihtimalini; \%20 olasılıkla 4000 TL kaybetme intimaline tercih etmektedir. Bireyler olasılığın sadece $\% 5$ daha yüksek olmasına karşın, kaybedilecek değerin düşük olduğu seçeneği, kaybedilecek değerin daha yüksek olduğu seçeneğe tercih etmektedir. Yani \%5 daha fazla risk alarak 3000 TL kaybetmeyi, 4000 TL kaybetmeye tercih etmektedir.

Problem 9'da ise katılımcılar, \%45 olasılıkla 6000 TL kaybetme seçeneğini; \%90 olasılıkla 3000 TL kaybetme seçeneğine tercih etmektedir. Anlaşılan o ki katılımcılar \%90 olasııı̆ı kesinmiş gibi değerlendirerek, kayıplarının 3000 TL daha fazla olma ihtimaline rağmen daha düşük olasılığı (\%45), daha yüksek olasılığa (\%90) tercih etmektedir. Kaybetme olasılığının daha düşük olduğu seçeneğin değerinin daha yüksek olmasına rağmen kaybetme olasılığının yüksek olduğu seçeneklere tercih edilmesi, bireylerin kayıplarını azaltma konusunda daha fazla risk alma eğilimine sahip olduklarını göstermektedir.

\section{Problem 10: $\mathbf{N}=180$}

Türkiye'nin 600 kişinin ölümü ile sonuçlanabilecek bir salgın hastalıkla karşı karşıya olduğu ihtimalini göz önünde bulundurun. Bu salgınla baş edebilmek için iki ayrı aşı bulunmakta. Bu aşılardan bir tanesi Alfa, diğer ise Beta:
A. Eğer Alfa asisi uygulansa, 200 kişinin hayatı kurtarılacak
[57]
B.
Beta aşısının kullanılması durumunda 600 kişinin kurtarılma ihtimali 3'te 1 
iken; hiç kimsenin kurtarılamama ihtimali 3'te 2'dir.

\section{Problem 11: N= 181}

Aynı salgın hastalıkla baş etmek için bu sefer iki farklı aşı önerilmekte. Bu aşılar Ceta ve Deta olarak adlandırımakta:

C. Eğer Ceta kullanılırsa, 400 kişi ölecek.

D. Deta'nın kullanılması durumunda hiç kimsenin ölmeme ihtimali 3'te 1 iken; 600 kişiden 600'ünün ölme ihtimali 3'te 2'dir.

Problem 13 ve 14, bireylerin risk tercihlerinin yanı sıra, bir problemin sunuluş şeklinin katılımcıların tercihlerinde neden olduğu değişkenliği tespit etmeyi amaçlamaktadır. Buna göre A seçeneği, elde edilecek sonucu olumlu ve kesin bir çerçeveden sunarken; B seçeneği, elde edilecek sonucu olasılıksal bir çerçeveden sunmaktadır. Problem 11 ise, aynı sonuçları bu sefer olumsuzluk çerçevesinden sunmaktadır. İki problem de aslında aynı sonuca işaret etmektedir. Problem 10'da olduğu gibi, seçenekler olumlu bir çerçeveden (hayatın kurtarılması olarak) sunulduğunda katılımcılar kesin sonucu, olası sonuca tercih etmektedir. Ancak seçenekler Problem 11'de olduğu gibi, aynı sonuçlar söz konusu olmasına rağmen olumsuz bir çerçeveden sunulduğunda katılımcıların, tercihlerini kesin seçenekten; olasılıksal seçeneğe değiştirdiği gözlemlenmektedir. Bu sonuç, çerçeveleme etkisinin bireylerin tercihlerinde nasıl bir etkiye sahip olduğunu göstermektedir.

\section{Sonuç}

Bu çalışmadan elde ettiğimiz sonuçlar, Kahneman ve Tversky'nin risk eğilimleri ve çerçeveleme etkisi konusundaki tezleri ile birebir aynı olmamakla birlikte; büyük ölçüde benzerlik göstermektedir. Katılımcılar, kazanmak söz konusu olunca mutlak/kesin sonuçları olasılıksal sonuçlara; kaybetmek söz konusu olunca da, olasılıksal sonuçları mutlak sonuçlara tercih etmektedirler. Yani insanlar, kazancın söz konusu olduğu durumlarda riskten kaçınmayl; kaybetmenin söz konusu olduğu durmalarda ise, risk almayı yeğlemektedirler. Aynı şekilde, ihtimal teorisinin öngördüğü gibi, çerçeveleme etkisi katılımclların tercihlerinde değişkenliğe neden olmaktadır. Rasyonel seçim kuramına göre seçeneklerin sunum şeklinin, tercihler üzerinde bir etkisi olmaması gerekmektedir. Ancak bu çalışmanın örneklemi kapsamındaki katılımcılar, seçeneklerin kazanç veya kayıp olarak sunulmasına göre aynı sonucu öngörüyor olmasına karşın, tercihlerinde değişikliğe gitmektedir.

Bu bağlamda elde edilen sonuçlar, büyük ölçüde ihtimal teorisi savlarının kültürel farklılıklara göre değişkenlik göstermediğine de işaret etmektedir. Kahneman ve Tversky bu çalışmaları, Amerikalı ve İsrailli katılımcılara 1970 ve 80 'li yıllarda yapmıştır. Yaklaşık yarım yüzyıl sonra sınırlı bir örneklem üzerin- 
de yapılmış olsa da, aynı model kullanılarak Türkiye'de yapılan bu çalışmanın kısmen de olsa benzer sonuçlar ortaya koyması, modelin geçerliliği ve genellenebilirliği açısından oldukça önemlidir. Ancak bu, Kahneman ve Tversky'nin ileri sürdüğü savların zaman ve mekân gözetmeksizin geçerliliği veya genellenebilirliği anlamına da gelmemelidir. Bu noktada sistematik olarak göze çarpan bir farklılığı belirtmekte fayda var: Sorulara verilen yanıtlar büyük ölçüde Kahneman ve Tversky'nin çalışmalarındaki bulgularla aynı yönde bir eğilimin varlığına işaret etse de, bu çalışmada ileri sürülen varsayımlar açısından bakıldığında, elde edilen sonuçların Kahneman ve Tversky'nin elde ettiği sonuçlardan daha düşük olduğu görülmektedir. Örneğin bu çalışmadaki katılımcıların \%75'i, Problem 1'deki A seçeneğini B seçeneğine tercih ederken; Kahneman ve Tversky'nin aynı sorunun B seçeneği için elde ettiği oran \%82'dir. Bu farklılık neredeyse tüm diğer sorular için de söz konusudur. Ancak aradaki farkın neden kaynaklandığına veya kültürel sebeplere bağlanıp bağlanamayacağına dair elimizde yeterli veri bulunmamaktadır. Modelin başka ve çok daha kapsamlı örneklemlerle desteklenmesi gereklidir. Eğer bu çalışmayı belli bir üniversitenin öğrencileriyle sınırı tutmayıp Türkiye genelini yansıtabilecek temsil yetkinliğine ve büyüklüğüne sahip bir örneklem üzerinde yapmış olsaydık, belki de çok daha farklı sonuçlara ulaşabilirdik. Bu noktada söz konusu bu çalışmanın, daha kapsamlı bir çalışmanın ön alıştırması olarak değerlendirilmesi çok daha doğru olacaktır.

\section{Kaynakça}

Allais, M. (1979). "The So-called Allais Paradox and Rational Decisions under Uncertainty". M. Allais ve O. Hagen (ed.). Expected Utility Hypotheses and the Allais Paradox. (437-681). Dordrecht: Reidel Publishing.

Bar-Hillel, M. (1973). "On the Subjective Probability of Compound Events". Organizational Behavior and Human Performance. 9(3). 396-406.

Einhorn, H. J. ve Hogarth, R. M. (1986). "Decision Making under Ambiguity". Journal of Business. 59(4). 225-250.

Ellsberg, D. (1961)."Risk, Ambiguity and the Savage Axioms". Quarterly Journal of Economics. 75(4). 643-669.

Fischhoff, B., Goitein, B., Shapira, Z. (1981). "Subjective Expected Utility: A Model of Decision-Making". Journal of The American Soceity for Information Science. 32(5). 391- 399.

Fishburn, P. C. (1988). "Expected Utility: An Anniversary and a New Era". Journal of Risk and Uncertainty. 1. 267-283.

Friedman, M. ve Savage, L. J. (1948). "Utility Analysis of Choices Involving Risk". Journal of Political Economy. 56(4). 279-304. 
Hogarth, R. M. ve Makridakis, S. (1981). “Forecasting and Planning: An Evaluation". Management Science. 27(2). 115-138.

Kahneman, D. ve Tversky, A. (1979). "Prospect Theory: An Analysis of Decisions under Risk". Econometrica. 47. 263-291.

(1982). "Judgement under Uncertainty: Heuristics and Biases". Kahneman. P., Slovic, A., Tversky, D. (ed.). Judgment under Uncertainty: Heuristics and Biases. New York: Cambridge University Press.

341-350.

(1984). "Choices, Values, and Frames". American Psychologist. 39.

Markowitz, H. M. (1952). "The Utility of Wealth". Political Economy. 60(2). 15158.

Mosteller, F. ve Nogee, P. (1951). "An Experimental Measurement of Utility". Political Economy. 59(5). 371-404.

Tversky, A. (1969). "Intransitivity of Preferences". Psychological Review. 76(1). 31-48.

(1975). "A Critique of Expected Utility Theory: Descriptive and Normative Considerations". Springer. 9(2). 163-173.

Tversky, A. ve Kahneman, D. (1974). "Judgment under Uncertainty: Heuristics and Biases". Science: New Series. 185(4157). 1124-1131.

von Neumann, J. ve Morgenstern, O. (1944). Theory of Games and Economic Behavior. Princeton: Princeton University Press. 